\title{
Endoscopic Two-Port Technique for Orbital Tumors, A Combined Transnasal and Sublabial Approach: A Retrospective Case Study
}

\author{
Petr Matousek \\ University Hospital Ostrava: Fakultni Nemocnice Ostrava https://orcid.org/0000-0002-0930-6773 \\ Michaela Masárová \\ University Hospital Ostrava: Fakultni Nemocnice Ostrava \\ Jakub Lubojacký \\ University Hospital Ostrava: Fakultni Nemocnice Ostrava \\ Adam Kopecký \\ University Hospital Ostrava: Fakultni Nemocnice Ostrava \\ Jan Němčanský \\ University Hospital Ostrava: Fakultni Nemocnice Ostrava \\ Eva Misiorzová \\ University Hospital Ostrava: Fakultni Nemocnice Ostrava \\ Tomáš Krejčí \\ University Hospital Ostrava: Fakultni Nemocnice Ostrava \\ Pavel Kominek \\ University Hospital Ostrava: Fakultni Nemocnice Ostrava \\ Radim Lipina ( $\square$ radim.lipina@fno.cz) \\ Department of Neurosurgery, University Hospital Ostrava https://orcid.org/0000-0002-8388-1311
}

\section{Research Article}

Keywords: orbital tumors, endoscopy, transnasal approach, sublabial transantral approach, two port surgery

Posted Date: May 17th, 2021

DOI: https://doi.org/10.21203/rs.3.rs-407897/v1

License: @ (1) This work is licensed under a Creative Commons Attribution 4.0 International License. Read Full License 


\section{Abstract}

Background: We investigated the indications for a combined endoscopic transnasal and sublabial transantral approach for the surgical treatment of orbital lesions.

Methods: This case study enrolled 10 patients scheduled for endoscopic transnasal surgery for treating orbital lesions from 2009 to 2020. When the tumor was localized to the medial part of the orbit, patients underwent endoscopy with a transnasal mononostril approach. Alternatively, when the tumor was localized to the mediocaudal part of the orbit, and when instrument maneuverability was limited, the transnasal approach was combined with a sublabial transantral approach. This two-port surgery approach was preferred over a trans-septal approach (binostril approach), because the two-port approach could expand the operating field in the medial part of the orbit. Here, we evaluated the indications, complications, and advantages of monoportal and combined two-portal approaches.

Results: Among the 10 patients enrolled, 8 (80.0\%) underwent surgery with the transnasal mononostril approach, and 2 (20.0\%) underwent surgery with the combined transnasal mononostril and sublabial transantral approach. In the two latter cases, visualization of the operation field was excellent, and there was adequate room for manipulating instruments. No dysesthesia in the region of infraorbital nerve was observed postoperatively.

Conclusion: The combination mononostril-transantral approach provided the space necessary to maneuver instruments and to visualize the surgical field in treating mediocaudal orbital lesions. This two-portal approach enabled extensive resections of intraconal lesions; thus, it could be considered a suitable alternative to the binostril approach.

\section{Background}

The choice of surgical approach for orbital lesions - though all approaches are extremely demanding - is dictated mainly by the location of the lesion [1, 2]. In addition, the anatomy of the orbit calls for microsurgical preparation. That's why three- or four-handed techniques are often required; thus, the emphasis is placed on the width of the access corridor $[3,4]$.

To achieve medial and mediocaudal intraorbital lesions is mostly used an endoscopic transnasal approach, that typically provides sufficient space for maneuvering the endoscope and 2 instruments with the three-handed technique [1, 2, 5]. But in some cases, instrument maneuverability is limited and the surgical field have to be enlarged [5].

The present study aimed to evaluate the combined transnasal and transantral approach for orbital tumors and to assess the different advantages of a pure mononostril approach and the combined approach. Only a few studies have described the combined transnasal and sublabial transantral approach $[6,7]$.

\section{Materials And Methods}

This case study included patients that had undergone transnasal endoscopic resections of orbital tumors (the medial part of orbit) at the University Hospital Ostrava, between 2009 and 2020. The endoscopic approach was indicated for patients with medial or mediocaudal orbital lesions, either intraconal or extraconal.

Patients were treated with the surgical mononostril approach, with either the 3- or 4-handed technique (two surgeons). When instrument maneuverability was limited during tumor dissection, the transnasal approach was combined with a sublabial transantral approach.

Computed tomography (CT) and magnetic resonance (MR) investigations were conducted pre-operatively. Additionally, an endoscopy of the nasal cavity and an ophthalmological examination were carried out.

- After placing the patient under general anesthesia and navigational alignment (Medtronic StealthStation), the ophthalmologist performed a dynamic retraction of the medial and (when necessary) inferior rectus muscles. A sphenoethmoidectomy was performed. The middle turbinate was resected to improve instrument maneuverability.

The lamina papyracea was removed with Kerrison rongeurs or a Freer elevator. For inferomedial tumors, the inferior orbital wall was thinned and partially removed, medially, to the infraorbital nerve. The periorbita was opened with a sickle knife or diamond knife to the extent necessary for tumor resection. The tumor location was confirmed with navigation.

- When the surgical space in the transnasal corridor was inadequate for performing a 4-handed technique, a small anterior maxillary opening, approximately $2 \times 2 \mathrm{~cm}$, was made for a sublabial approach. An endoscope and one other instrument, typically suction, were introduced through the opening. At the end of the procedure, suturing was performed with absorbable sutures. 
- Extraconal lesions were accessed by making a posteroanterior incision in the periorbita. Intraconal lesions were accessed through a surgical window between the inferior and medial orbital rectus muscles, which were retracted as needed, into the frontal sinus with a ball probe. Identification of the rectus muscles was aided intra-operatively by retracting a suture placed around the rectus at its insertion into the globe. No reconstruction of periorbital defects was carried out.

- An ophthalmological examination and endoscopy were conducted postoperatively, at one day, one week, and three weeks after surgery. Patients were strictly instructed not to blow the nose, due to the risk of orbital emphysema. Patients were encouraged to perform nasal irrigation with saline 10 times per day for two weeks. The extent of resection was determined with MR imaging. Postoperative symptoms, results, and complications were observed.

\section{Results}

Between 2009 and 2020, 10 patients (4 males and 6 females, mean age: 61 years, range: 29 to 83) underwent surgery with the transnasal endoscopic approach (Table 1). The intraorbital lesions were located extraconally, in 1 case, and intraconally in 9 cases. A mononostril transnasal approach was performed in $8 / 20$ (80.0\%) cases, and a combination mononostril and sublabial approach was performed in $2 / 10$ (20.0\%) cases. The sublabial approach was indicated, when the surgical space was inadequate for maneuvering instruments with multi-handed techniques.

In the two patients that required the two-port approach, the tumor was located in the inferomedial orbit; therefore, the transantral approach provided the shortest direct route to the lesion (Table 1).

Table 1

Patients that underwent the two-port approach for resecting lesions in the orbit

\section{Case 1}

- Patient: female, 53 years old;

- Symptom: proptosis;

- Examinations: CT and MR demonstrated a well-defined extra- and intraconal lesion, with heterogeneous enhancement on post-contrast images, and spatial displacement of the optic nerve (Fig. 1);

- Diagnosis: histology identified a cavernous hemangioma;

- Outcome: no residua on postoperative MR; minor hematoma of the lower eyelid, no diplopia, vision normal.

\section{Case 2}

- Patient: female, 70 years old;

- Clinical history: breast carcinoma treated 9 years prior to this study; treated with breast ablation, exenteration of the axilla, and adjuvant radiochemotherapy;

- Symptoms: intermittent diplopia for 6 months pre-operatively, with increasing proptosis (2 mm) for 3 months; restricted globe movement in all directions, particularly in moving upwards and in abduction;

- Examinations: CT and MR demonstrated an intraconal tumor infiltrating the inferior rectal muscle, with homogeneous post-contrast enhancement, T1 and T2 hypointensities; it was softly defined, and inferior to the optic nerve (Fig. 2);

- Diagnosis: histology identified it as a metastasis of breast cancer,

- Outcome: diplopia with downward eye movements persisted.

In one of these two cases, a total gross resection was achieved. The lesion was identified histologically as a cavernous hemangioma. The other patient had a metastatic lesion from breast cancer, and a partial resection and orbital decompression were performed.

The postoperative results and complications of all orbital endoscopic approaches are shown in Table 2. In the combined approaches, no emphysema, facial edema, or dysesthesia were observed postoperatively in the region of infraorbital nerve innervation. 
Table 2

Patient demographics, tumor characteristics, approach, and outcome

\begin{tabular}{|c|c|c|c|c|c|c|c|c|c|}
\hline Patient & $\begin{array}{l}\text { Age } \\
\text { (v) }\end{array}$ & Sex & Symptoms & $\begin{array}{l}\text { Intraconal/ } \\
\text { extraconal }\end{array}$ & Approach & Diagnosis & $\begin{array}{l}\text { Resection } \\
\text { outcome }\end{array}$ & Complications & $\begin{array}{l}\text { Postoperative } \\
\text { symptoms }\end{array}$ \\
\hline 1 & 72 & M & $\begin{array}{l}\text { pain, } \\
\text { ophtalmoplegia, } \\
\text { vision loss }\end{array}$ & intraconal & transnasal & $\begin{array}{l}\text { metastatic } \\
\text { adenocarcinoma }\end{array}$ & partial & - & unchanged \\
\hline 2 & 59 & M & diplopia & intraconal & transnasal & neurofibroma & partial & $\begin{array}{l}\text { temporary } \\
\text { paresis; } \\
\text { cranial nerve } \\
\text { III }\end{array}$ & $\begin{array}{l}\text { diplopia } \\
\text { resolved }\end{array}$ \\
\hline 3 & 67 & $\mathrm{~F}$ & diplopia & extraconal & transnasal & angioleiomyoma & total & - & $\begin{array}{l}\text { diplopia } \\
\text { resolved }\end{array}$ \\
\hline 4 & 53 & $\mathrm{~F}$ & proptosis & intraconal & $\begin{array}{l}\text { transnasal+ } \\
\text { sublabial }\end{array}$ & $\begin{array}{l}\text { cavernous } \\
\text { hemangioma }\end{array}$ & total & - & $\begin{array}{l}\text { proptosis } \\
\text { improved }\end{array}$ \\
\hline 5 & 29 & $\mathrm{~F}$ & diplopia, pain & intraconal & transnasal & $\begin{array}{l}\text { cavernous } \\
\text { hemangioma }\end{array}$ & total & $\begin{array}{l}\text { lower lid } \\
\text { hematoma }\end{array}$ & $\begin{array}{l}\text { diplopia } \\
\text { resolved, pain } \\
\text { resolved }\end{array}$ \\
\hline 6 & 70 & $\mathrm{~F}$ & $\begin{array}{l}\text { proptosis, } \\
\text { diplopia }\end{array}$ & intraconal & $\begin{array}{l}\text { transnasal+ } \\
\text { sublabial }\end{array}$ & $\begin{array}{l}\text { metastatic } \\
\text { breast } \\
\text { carcinoma }\end{array}$ & partial & - & $\begin{array}{l}\text { diplopia } \\
\text { improved }\end{array}$ \\
\hline 7 & 72 & $\mathrm{~F}$ & diplopia & intraconal & transnasal & lymphoma & partial & - & unchanged \\
\hline 8 & 83 & $M$ & diplopia & intraconal & transnasal & $\begin{array}{l}\text { metastatic } \\
\text { neuroendocrine } \\
\text { carcinoma }\end{array}$ & near total & - & $\begin{array}{l}\text { diplopia } \\
\text { improved }\end{array}$ \\
\hline 9 & 39 & M & diplopia, pain & intraconal & transnasal & $\begin{array}{l}\text { inflammatory } \\
\text { pseudotumor }\end{array}$ & partial & - & $\begin{array}{l}\text { diplopia } \\
\text { unchanged, } \\
\text { pain resolved }\end{array}$ \\
\hline 10 & 71 & $\mathrm{~F}$ & $\begin{array}{l}\text { proptosis, } \\
\text { diplopia, }\end{array}$ & $\begin{array}{l}\text { extraconal/ } \\
\text { intraconal }\end{array}$ & transnasal & $\begin{array}{l}\text { squamous cell } \\
\text { carcinoma }\end{array}$ & partial & - & unchanged \\
\hline
\end{tabular}

\section{Discussion}

The present study described the endoscopic transnasal approach for orbital lesions medial and inferior to the optic nerve. This approach had been shown to provide excellent visualization of the surgical field without having to resort to globe retraction [1, 4, 8]. The downside of this approach is that the width of the surgical corridor might be insufficient for the multi-handed techniques required for surgery in the orbit.

In the mononostril approach, there is typically sufficient space for the 2- and 3-handed techniques routinely employed for extraconal lesions. For intraconal lesions that require a 4-handed approach, instrument maneuverability may be limited. Therefore, further expansion of the surgical corridor may be required $[5,9]$. Sufficient space can be gained by resecting the middle turbinate or by creating a corridor through the nasal septum (binostril approach), either with a posterior septectomy, for lesions in the orbital apex, or by creating a septal window, for intraorbital lesions [5]. The trans-septal approach provides the surgeon with a good angle for dissection, but can increase nasal morbidity and may adversely influence nasal function.

An alternative approach is to create an auxiliary sublabial transantral corridor. Then, an endoscope and one other instrument can be introduced through the anterior wall of the maxillary sinus. This approach provides the shortest direct route to caudal orbital lesions. Few studies have investigated the combination transnasal-sublabial approach to the orbit [6, 7]. Alimomahadi et al. described their treatment experience with the combined endonasal and sublabial transantral approach for 4 patients with orbital and pterygopalatine fossa pathologies [6]. Har-El et al. described this combined approach for 2 patients with orbital apex lesions. They highlighted the advantages of this approach: it provided excellent visualization and avoided the struggle between surgical instruments and the endoscope, which is often encountered with the transnasal approach alone [7].

In our study, the combined mononostril transnasal and sublabial transantral endoscopic approach was employed in two patients with tumors in a mediocaudal location (Fig. 3). In these cases, the single nostril approach alone did not permit sufficient maneuverability for the instruments, even after performing a middle turbinate resection. However, the sublabial approach allowed the introduction of an endoscope and other 
instruments as necessary, and it provided excellent visualization of the anterior and lateral borders of the tumor (Fig. 4). The endoscope did not hinder the manipulation of the surgical instruments, and the field of view was sufficiently wide without resorting to an orbital bone resection.

Introducing an endoscope requires a fenestration greater than $4 \mathrm{~mm}$ wide, and at least 7-8 $\mathrm{mm}$, when irrigation is required. A more extensive resection $(2 \times 2 \mathrm{~cm})$ of the anterior maxillary bone allows other instruments (typically, suction) to be introduced alongside the endoscope. We considered this approach beneficial for several reasons: it provided excellent visualization of the surgical field without interference from the instruments introduced transnasally; the procedure was relatively simple and brief; and the technique is generally familiar among otolaryngologists. Moreover, this approach reduced the risk of interfering with nasal function, compared to the trans-septal approach, which requires a resection or incision of the nasal septum.

The sublabial transantral approach might lead to postoperative complications, including dysesthesia in regions innervated by the trigeminal nerve, emphysema, and facial edema. These complications occur mainly with the classic wide approach (the Caldwell-Luc procedure), which involves a large resection of the anterior wall of the maxillary sinus. However, the minimally invasive approach is typically associated with only temporary complications, such as facial hypoesthesia [7]. No complications were observed in our study.

The dreaded complications of enophthalmos and diplopia, which may arise with infraorbital resections, can also occur with the transantral approach. Having said that, the extent of resection is no greater with the combined approach than with the transnasal approach. We observed no recurrent diplopia postoperatively.

The combination mononostril transnasal and sublabial transantral approach ensured sufficient space for multi-handed techniques, allowed the shortest direct route to mediocaudal lesions, and provided a suitably wide field of view. This approach could be considered an appropriate alternative to the binostril approach.

\section{Conclusion}

The combined mononostril endonasal and sublabial transantral approach is a safe, easy-performed and very effective method that enable the utilization of multi-handed techniques. It allows free and comfortable instrument maneveurs to reach intraconal lesions located in the inferomedial orbit when space in the nasal cavity is restricted. It represents a suitable and relatively elegant alternative to the binostril approach.

\section{Declarations}

- Ethics approval and consent to participate: This study has been performed in accordance with the Declaration of Helsinki, was approved by the Ethics Committee of the University Hospital Ostrava, Czech Republic, Ref. Number: 75/2021. Informed consent to participate was obtained from the patients presented in the work.

- Consent for publication: Consent to publish was obtained from the patients described in this study.

- Availability of data and materials: Not applicable

- Competing interests: The authors declare no conflict of interest.

- Funding: This work was supported by the grant SGS10/LF/2021, Faculty of Medicine University of Ostrava

- Authors' contributions: All authors have read and approved the manuscript. PM performed surgery and was the major contributor to writing the manuscript; MM analyzed data and contributed to writing the manuscript; JL analyzed data and reviewed the literature; AK performed surgery and revised drafts of the manuscript; JN revised manuscript drafts; EM reviewed the literature; TK performed surgery; PK revised manuscript drafts; RL performed surgery and revised manuscript drafts.

- Acknowledgements: Not applicable

\section{References}

1. Castelnuovo P, Dallan I, Locatelli D, Battaglia P, Farneti P, Tomazic PV, et al. Endoscopic transnasal intraorbital surgery: our experience with 16 cases. Eur Arch Otorhinolaryngol. 2012;269(8):1929-35.

2. Muscatello L, Seccia V, Caniglia M, Sellari-Franceschini S, Lenzi R. Transnasal endoscopic surgery for selected orbital cavernous hemangiomas: our preliminary experience. Head Neck. 2013;35(7):E218-20.

3. Bleier BS, Castelnuovo P, Battaglia P, Turri-Zanoni M, Dallan I, Metson R, et al. Endoscopic endonasal orbital cavernous hemangioma resection: global experience in techniques and outcomes. Int Forum Allergy Rhinol. 2016;6(2):156-61.

4. Paluzzi A, Gardner PA, Fernandez-Miranda JC, Tormenti MJ, Stefko ST, Snyderman CH, et al. "Round-the-Clock" Surgical Access to the Orbit. J Neurol Surg B Skull Base. 2015;76(1):12-24. 
5. Healy DY Jr, Lee NG, Freitag SK, Bleier BS. Endoscopic bimanual approach to an intraconal cavernous hemangioma of the orbital apex with vascularized flap reconstruction. Ophthalmic Plast Reconstr Surg. 2014;30(4):e104-6.

6. Arai Y, Kawahara N, Yokoyama T, Oridate N. Endoscopic transnasal approach for orbital tumors: A report of four cases. Auris Nasus Larynx. 2016;43(3):353-8.

7. Melder K, Zwagerman N, Gardner PA, Wang EW. Endoscopic Endonasal Approach for Intra- and Extraconal Orbital Pathologies. J Neurol Surg B Skull Base. 2020;81(4):442-9.

8. Har-El G. Combined endoscopic transmaxillary-transnasal approach to the pterygoid region, lateral sphenoid sinus, and retrobulbar orbit. Ann Otol Rhinol Laryngol. 2005;114(6):439-42.

9. Alimohamadi M, Hajiabadi M, Gerganov V, Fahlbusch R, Samii M. Combined endonasal and sublabial endoscopic transmaxillary approach to the pterygopalatine fossa and orbital apex. Acta Neurochir (Wien). 2015;157(6):919-29.

\section{Figures}

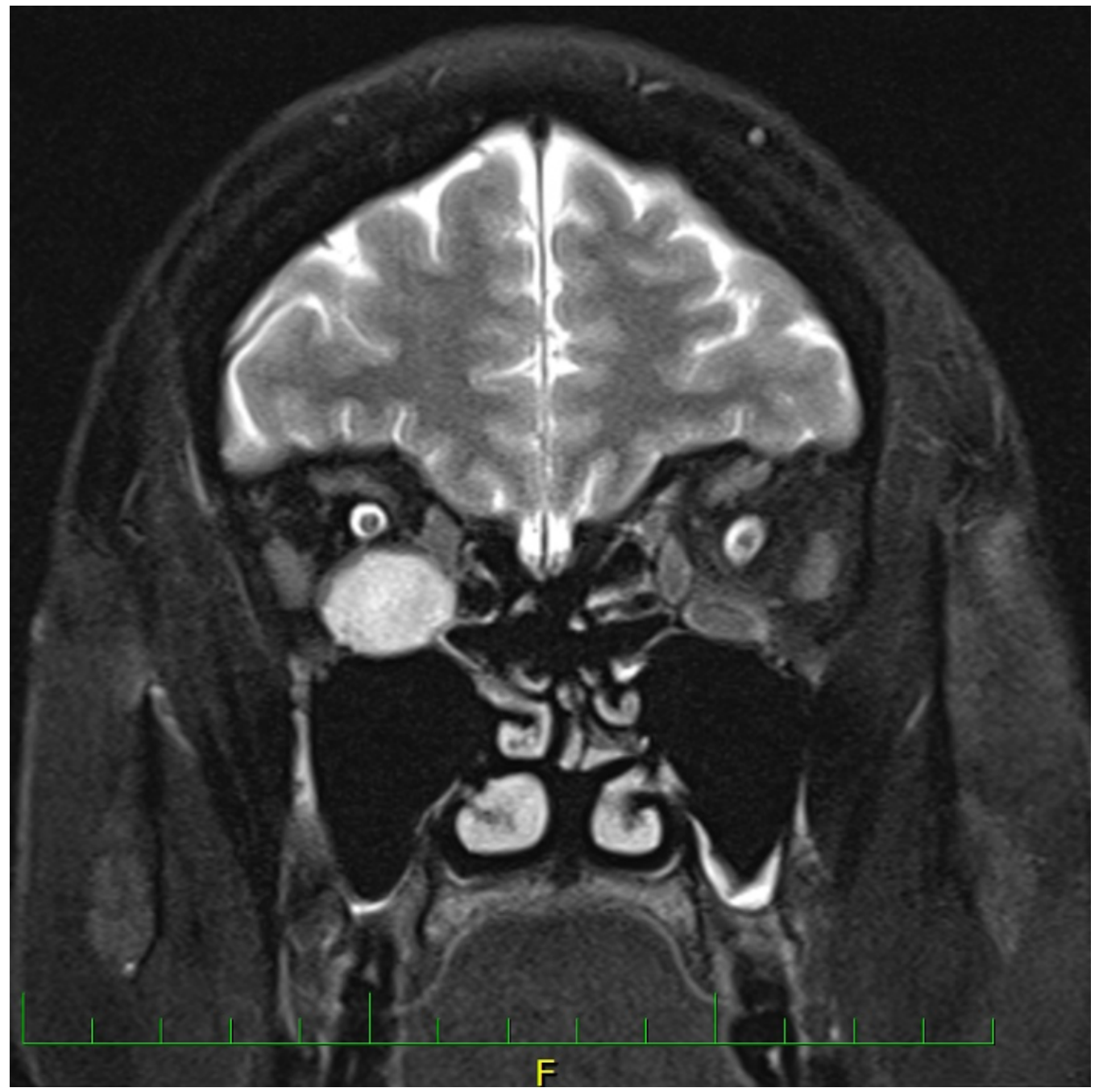

\section{Figure 1}

Magnetic resonance image of an orbital hemangioma, coronal view 


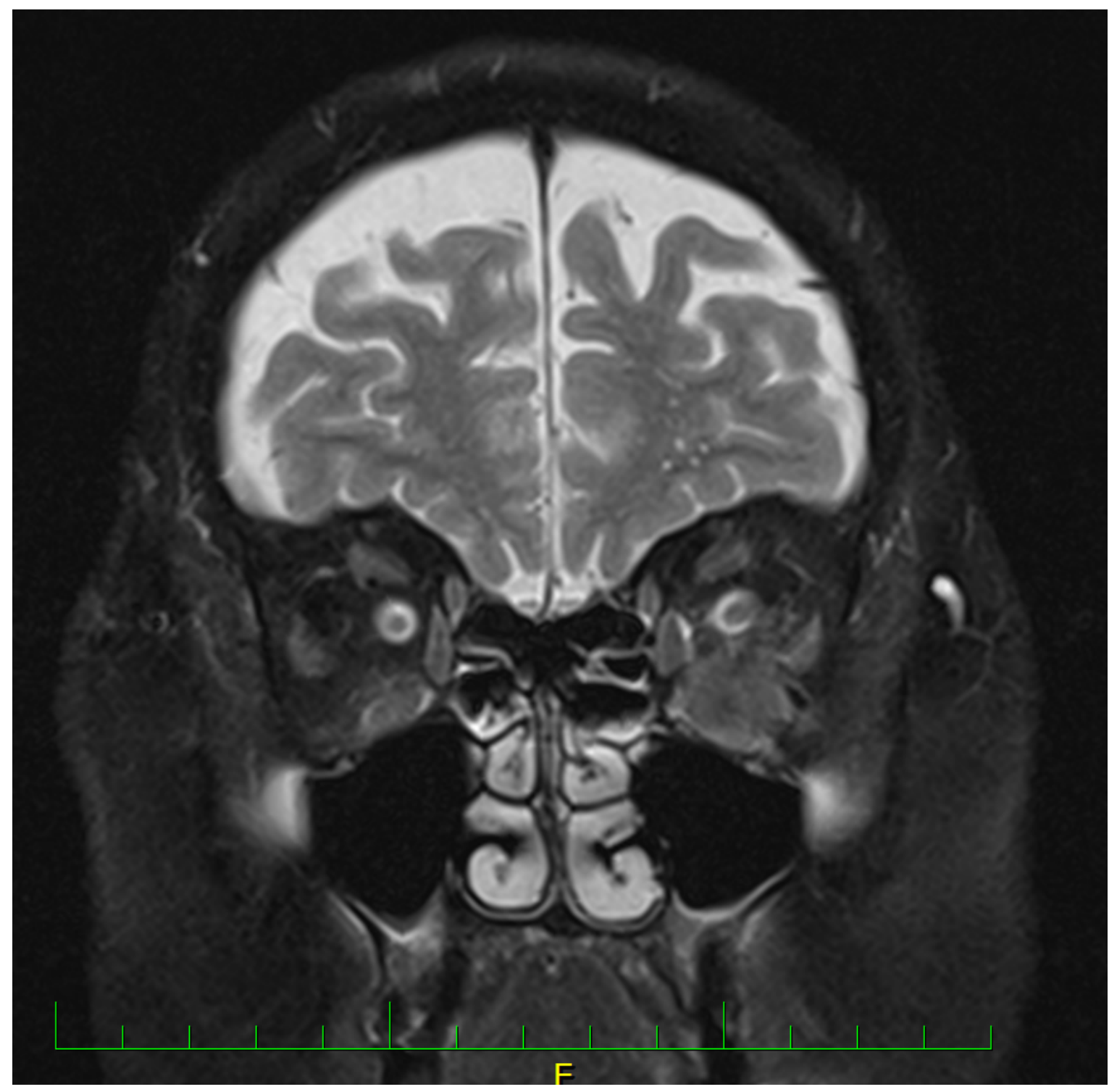

Figure 2

Magnetic resonance image of metastasis from breast cancer, coronal view 


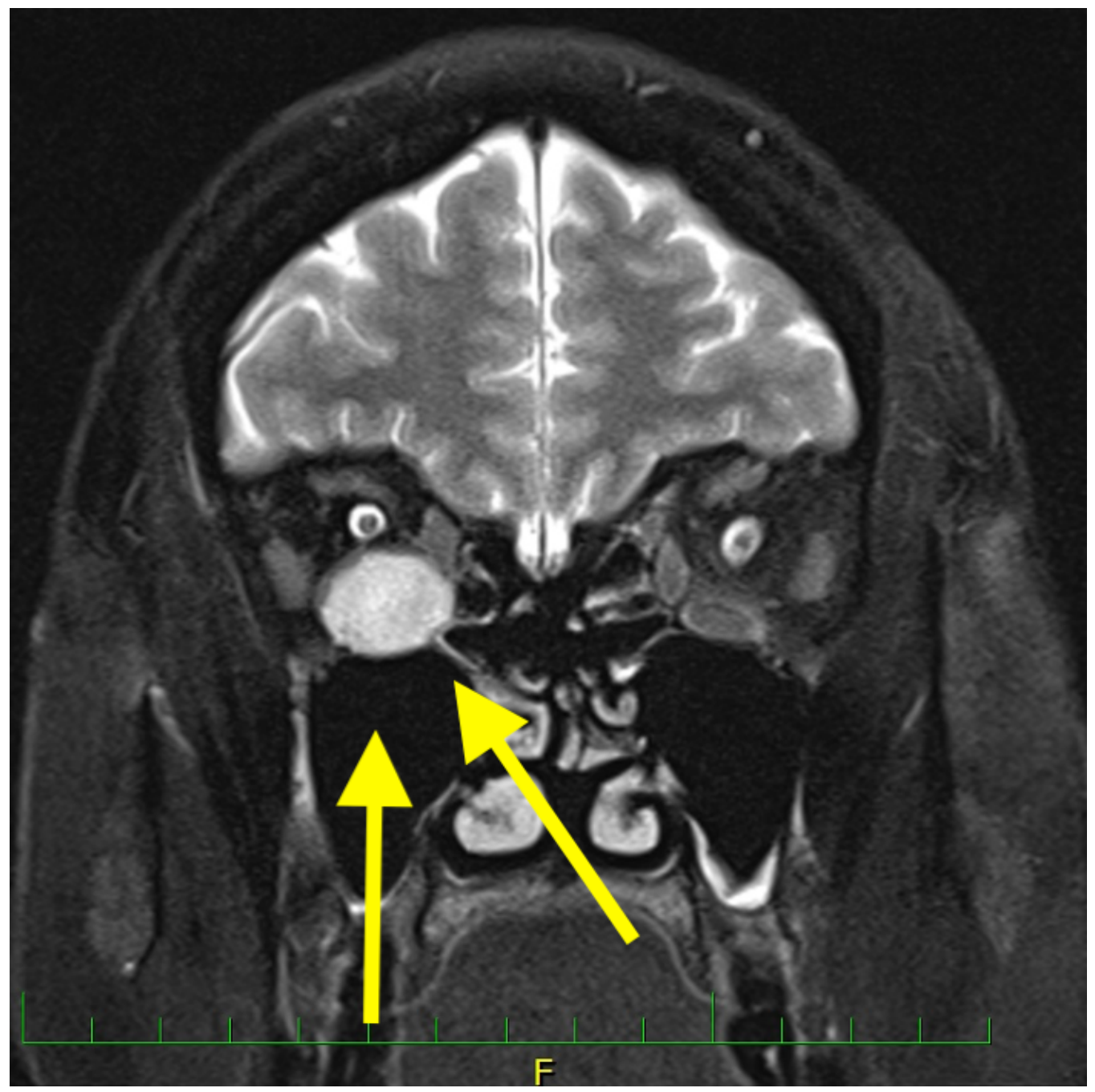

\section{Figure 3}

Schematic diagram of the two-port transnasal and transantral approach

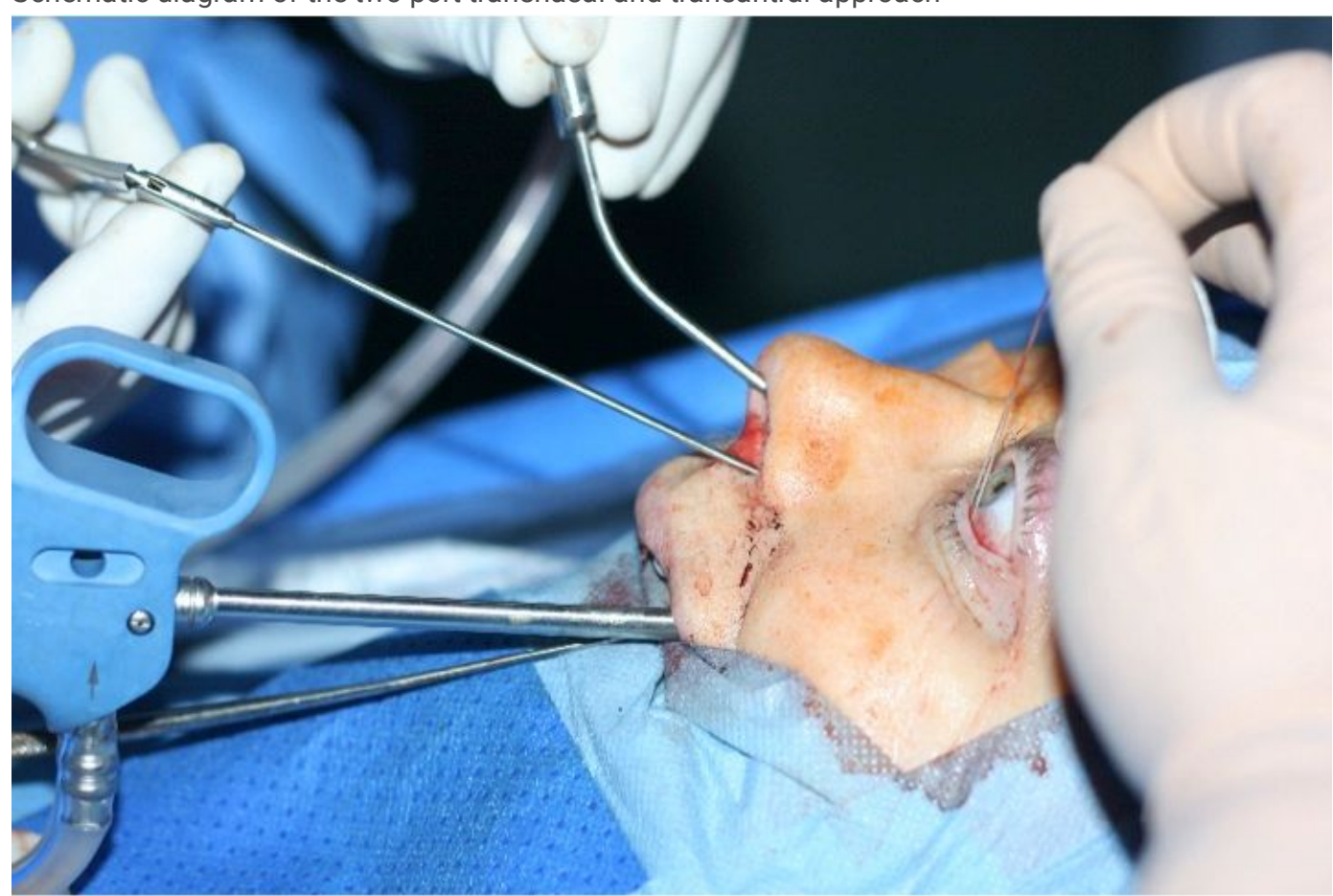

Figure 4 
Perioperative view of the combination transnasal-transantral approach

Page 9/9 